\title{
A Lost Idyll of Connection?
}

\author{
Michael Ashby
}

Published online: 23 December 2021

(C) Journal of Bioethical Inquiry Pty Ltd. 2021

Keywords COVID-19 - Connection - Trust . Distress · Grief

As we age, it is so easy to slip into the trap of lamentations: that there were salad days when values were nobler and better upheld, civility reigned, and localism meant that people were more connected. Of course this is not altogether true, and there is much in the past social structures in race, gender, and hierarchy, for instance, that are in slow painful processes of change for the better. However, the river of time brings gains and losses, and human connection appears to be one casualty for many in the modern world, especially with the remorseless grind of the continuing pandemic which is the subject, once again, of a number of papers in this edition of the Journal of Bioethical Inquiry.

Recent research work by the American grief expert Robert Niemeyer and colleagues in Memphis and Australia, show very high levels of distress and impairment of function for those who have experienced the death of close people from COVID-19, in fact amongst the highest recorded for trauma and disasters in the past. Some of the key indices that drove

M. Ashby $(\bowtie)$

Cancer, Chronic Disease and Sub-Acute Stream,

Royal Hobart Hospital, Tasmanian Health Service,

School of Medicine, Royal Hobart Hospital, University

of Tasmania, Hobart, TAS 7000, Australia

e-mail: michael.ashby@ths.tas.gov.au these high scores are related to people dying alone and limited funeral rites-in other words, it appears that, perhaps unsurprisingly, grief in this pandemic has been aggravated by limits to intimacy and connection, and that we can cope with almost anything with human solidarity and connection (Niemeyer 2021).

An important positive feature of good connection is good behaviour towards others even in difficult circumstances, a sense of civility, good manners, and courtesy. The problem of bioethics as a discipline is that civility is so situation and culture dependent, maybe better understood by anthropology than philosophy. We can differ widely as to what we consider to be good manners, especially in a time of contagion and its fears. David Shaw (2021) looks at manners and the difficulty of speaking up for violations by other members of the public, or even within families, about mask wearing, social distancing etc. Are the bad manners in the feedback or the breach itself, thereby risking infecting others? That there has been at times arbitrary, rigid, and at times pointless enforcement, is probably true everywhere, and maybe some people welcome the opportunity to be enforcers with others who appear to threaten the collective well-being of the community. Or maybe with the threat of mortality, the impulse to conform and punish outliers is part of a broader defence of the culture and its legacy, as Terror Management Theory urges us to believe. In other words, we are more likely to deal harshly with others if our own mortality is in question 
(Menzies and Menzies 2021). Shaw points out that rules need to be simple and consistent, and their purpose must be clear for widespread compliance.

Ho and Huang (2021) write about the importance of public health authorities engendering trust in the community by being transparent about the reasons for, in this instance, evolving and changing mask regulations in the United States. Samuel et al. (2021) analyse the complexity of building public trust in a U.K. COVID-19 app and from a small number of end-user interviews, conclude that institutional trust doesn't necessarily align with individual engagement for such a tool.

Construction of any provisional reality needed to live life requires some assessment of the future. Although no prediction is cast iron certainty, in specialized areas outside our sphere of knowledge or experience, it is easy to forget that, no matter how elaborate and well thought out, no prediction or modelling gets it all right. Danger comes when predictive models in intimidating areas of science allow the subjective to masquerade as objective, where the assumptions that underpin modelling are unquestioned. Modern life, and its media, is full of predictions, whether they be sporting, financial, electoral, or meteorological, forecasting is a daily feature of news and analysis. In the last two years, the predictive models about COVID-19 spread have become ubiquitous and influence every aspect of daily life. Cooper, Dimitriou, and Arandjelovíc (2021) from St Andrew's University, offer an analytical challenge to modelling about COVID-19 spread that informed early 2020 U.K. government responses to the pandemic.

The old have, for instance, sent the young to die in wars for aeons, but rarely has intergenerational solidarity been as severely tested, and questioned, as in the recent pandemic. Young people, who tend not to get very sick with COVID-19 have been asked to endure prolonged massive disruption to social life, work, education, and entertainment to mainly protect the older population who do get sick and may die. Sydney Campbell (2021) discusses the neglect of young voices in the pandemic discourse, and characterizes this as "adultcentrist," and asks if it is ethically permissible, even during a pandemic.

Wilkinson, Giubilini, and Savulescu (2021) argue that those, including Roman Catholics, who object to vaccines in which aborted foetuses had a role in the manufacturing process, should only be able to choose another vaccine if it is consistent with public health policy, and any additional cost is met by the individual rather than the community.

Tian (2021) contributes further to the ongoing discussion about triage for ventilator access management to severely ill COVID-19 patients. They propose consideration of ethics committees, at arm's length from the clinical bedside decision-making process, to advise when there is genuine ventilator access scarcity. In these more extreme scenarios it becomes likely that doctors are forced to choose who is ventilated, and who is not, on values based criteria rather than solely medical ones, and hence independent ethics input is warranted.

Ćurković et al. (2021) report on the Croatian study of ethical issues amongst doctors and nurses in intensive care units in that country. They highlight some of the differences in approach and context experienced by doctors and nurses and note a common lack of guidance and framework for end-of-life decisionmaking in that country. This once again highlights the fact that treatment abatement and palliative care deployment are fragile matters for clinicians in systems where prolongation of life and recognition of dying are subject to overriding bioethical and legal forces that still suggest that the dying should be treated as if they can be cured. Clinicians need to be educated and supported to talk to patients and families about frailty, old age, chronic disease burden, including dementia, and the pathways to death. This allows preparation for death by overtly dealing with the dying process in time to deploy good palliative care, rather than assuaging perceived causal anxiety with medically driven last-ditch treatment attempts that distract from the person's real needs and divert health resources from more effective use for those who can benefit. A death-friendly policy and legal framework is needed in all jurisdictions to address dying in the age of ageing and chronic diseases: with policies and procedures, and where needed, laws, that support advance directives, goals of care, limitation of medical treatment, and appropriate coronial scrutiny that truly understands palliative care: that ultimately death is not avoidable or preventable.

Two papers deal with philosophical issues. The first addresses the perennial clash of "geo-philosophy," in which hard line analytical philosophy (with strong roots in the Anglo-Saxon scholarly world despite strong European origins) is pitted against 
a more speculative continental (European) variant. Hub Zwart (2021) explains that so-called continental philosophy allows the importance of etymology in understanding ethical concepts. Rather than seeking only to nail down with precision a particular term regardless of historical use and meaning, continental philosophy makes use of this etymological usage history rather than dismissing it. To many outside the world of academic philosophy, the appeal of the continental approach for the study of bioethics is that the softer more nuanced analysis sits, in some ways, more comfortably with the "crooked timber" of human life, especially when trying to adopt a multidisciplinary view of issues in health and life sciences. One only needs to read the account of the late English philosopher, broadcaster, and author Bryan Magee (1997) who transferred from what he felt to be the straight jacket of Oxford logical positivism to Yale where he could study the philosophy of the word around him in a more continental academic environment. Those in analytical philosophy however would argue that the time spent with the drill sergeant major working rigorously within the framework of logic and science is the only way to make real progress of philosophical worth. No doubt philosophers might well also argue that we should not be seeking consolations or solutions for bioethical situations in philosophy per se. In a second article on philosophy, Kornu (2021) criticizes Avicenna's "mental dissective logic" as dehumanizing.

The onward march of voluntary assisted dying around the world continues with a recent court decision in Italy. Given the strong Roman Catholic traditional influence in that country this is significant, suggesting that secular forces are slowly eroding religious opposition to such issues. Turillazzi et al. (2021) report a recent case before the Italian constitutional court which, further to the legislation passed in 2017, seems to offer, the authors contend, pathways for physician assisted suicide in certain narrow circumstances.

Whilst working in healthcare has always been stressful, it is only in recent times that much attention has been paid to psychodynamic interventions to support and educate staff outside of the mental health professions, social work, and related professions. Techniques such as Schwartz rounds, Balint groups, debriefing meetings, and both individual and group clinical supervision are now being explored by health systems in recognition of the significant challenges to retaining a healthy workforce. Despite historical resistances, especially in medicine and nursing, health providers are realizing the time spent giving staff the chance to express the emotional impact of their work is a good investment. This author has always favoured the work of Hawkins and Shohet (2000), in which what they call a holistic and integrative model of supervision incorporates the worker's emotional response to the client's distress. Their humanistic model includes psychodynamic, humanistic, cognitive, behavioural, and systemic approaches centred on an intersubjective relationship between supervisor and supervisee. Most importantly, their model is based on Donald Winnicott's "good enough" mother model, where the clinician is "held" by the supervisor as he/she deals with the client's rage at the external world. Supervision then becomes a "container" for a triad of client, patient, and supervisor. Delany et al. (2021) discuss four different approaches to debriefing and clinical supervision, reflecting the theoretical basis of the different approaches available. The authors emphasize the ethical responsibility of being able to deal with the fallout for participants that may arise from opening up strong feelings and supporting those who have given their trust to the process. In an era of greater psychological awareness and increasing pressure within health systems, these supportive interventions, whether as regular features of continuing professional development plans or critical incident debriefing, will hopefully receive increasing attention.

Finally, Rimon-Zarfaty et al. (2021) report a comparative analysis study of regulatory frameworks in Austria, Germany, Israel, and the Netherlands with regard to embryo freezing and the medical versus social factors involved in policies and procedures. In our Recent Developments column, Gooding and Clifford (2021) look at electronic monitoring of patients in what they call "semi-automated" care, and a letter from Afsaneh Shirani (2021) points out how referencing in academic writing can be implicitly racist. This is yet another reminder of the way subtle and probably largely unconscious racism is woven into so many of our institutions and proceedings.

If we lament a lost intimacy of everyday life, it is perhaps to be found again closer to home, in more simple ways, and mindful of the recent Glasgow 
climate summit, maybe not only in better relationship with ourselves, and others, but also with nature.

Wendell Berry (2018), the American writer and farmer depicts a gentler more connected world in rural Kentucky, close to nature, those halcyon days of material limitation and spiritual plenty referred to earlier:

When despair for the world grows in me

And I wake in the night at the least sound

in fear of what my life and my children's lives may be,

I go and lie down where the wood drake

rests in his beauty on the water, and the great heron feeds.

I come into the peace of wild things

who do not tax their lives with forethought of grief.

As we approach the holiday season the season of goodwill attached to it, we would surely all agree the goodwill and civility in the conduct of human affairs should be present at all seasons and all places. We wish all our readers happy holidays, maybe some respite from the fears and pressures of the last two years, perhaps through connection with nature's beauty in your local version of Wendell Berry's quiet waters: a healing balm for differences and fears of all kinds, whatever the future may hold?

\section{References}

Berry, W. 2018. The peace of wild things. United Kingdom: Penguin.

Campbell, S. 2021. The ethics of adultcentrism in the context of COVID-19: Whose voice matters? Journal of Bioethical Inquiry 18(4): https://doi.org/10.1007/ s11673-021-10138-8.

Cooper, J., N. Dimitriou, and O. Arandjelovíc. 2021. How good is the science that informs government policy? A lesson from the U.K.'s response to the $2020 \mathrm{CoV}-2$ outbreak. Journal of Bioethical Inquiry 18(4): https://doi.org/ 10.1007/s11673-021-10130-2.

Ćurković, M., L. Brajković, A. Jozepović, et al. 2021. Endof-life decisions in intensive care units in Croatia-Pre COVID-19 perspectives and experiences from nurses and physicians. Journal of Bioethical Inquiry 18(4): https:// doi.org/10.1007/s11673-021-10128-w.

Delany, C., S. Jones, J. Sokol, et al. 2021. Reflecting before, during, and after the heat of the moment: A review of four approaches for supporting health staff to manage stressful events. Journal of Bioethical Inquiry 18(4): 10.1007/ s11673-021-10140-0.

Gooding, P.M., and D.M. Clifford. 2021. Semi-automated care: Video-algorithmic patient monitoring and surveillance in care settings. Journal of Bioethical Inquiry 18(4): https:// doi.org/10.1007/s11673-021-10139-7

Hawkins, P., and R. Shohet. 2000. Supervision in the helping professions. Buckingham: Open University Press.

Ho, A., and V. Huang. 2021. Unmasking the ethics of public health messaging in a pandemic. Journal of Bioethical Inquiry 18(4): https://doi.org/10.1007/s11673-021-10126-y.

Kornu, K. 2021. Anatomy of being, metaphysics of death: The case of Avicenna's logical dissection. Journal of Bioethical Inquiry 18(4): https://doi.org/10.1007/ s11673-021-10134-y

Magee, B. 1997. Confessions of a philosopher. London: Modern Library.

Menzies, R.E., and R.G. Menzies. 2021. How the fear of death shaped human society. Sydney: Allen and Unwin.

Rimon-Zarfaty, N., J. Kostenzer, L-K. Sismuth, and A. de Bont. 2021. Between "medical" and "social" egg freezing: A comparative analysis of regulatory frameworks in Austria, Germany, Israel, and the Netherlands. Journal of Bioethical Inquiry 18(4): https://doi.org/10.1007/ s11673-021-10133-z.

Samuel, G., F. Lucivero, S. Johnson, and H. Diedericks. 2021. Ecologies of public trust: The NHS COVID-19 contact tracing app. Journal of Bioethical Inquiry 18(4): https:// doi.org/10.1007/s11673-021-10127-x.

Shaw, D. 2021. Risk, responsibility, rudeness, and rules: The loneliness of the social distance warrior. Journal of Bioethical Inquiry 18(4): https://doi.org/10.1007/ s11673-021-10135-x.

Shirani, A. 2021. It is time to stop racial exclusion in scholarly citations. Journal of Bioethical Inquiry 18(4): https://doi. org/10.1007/s11673-021-10137-9

Tian, Y.J. 2021. The Ethical Unjustifications of COVID-19 Triage Committees. Journal of Bioethical Inquiry 18(4): https://doi.org/10.1007/s11673-021-10132-0

Turillazzi, E., A. Maiese, P. Frati, M. Scopetti, and M. Di Paolo. 2021. Physician-patient relationship, assisted suicide and the Italian Constitutional Court. Journal of Bioethical Inquiry 18(4): https://doi.org/10.1007/ s11673-021-10136-w.

Wilkinson, D., A. Giubilini, and J. Savulescu. 2021. Which vaccine? The cost of religious freedom in vaccination policy. Journal of Bioethical Inquiry 18(4): https://doi.org/ 10.1007/s11673-021-10148-6.

Zwart, H. 2021. Care for language: Etymology as a continental argument in bioethics. Journal of Bioethical Inquiry 18(4): https://doi.org/10.1007/s11673-021-10125-z.

Publisher's note Springer Nature remains neutral with regard to jurisdictional claims in published maps and institutional affiliations. 